\title{
ESPAÑA Y LAS ELECCIONES EUROPEAS
}

\section{SPAIN AND THE EUROPEAN ELECTIONS}

David Caldevilla Domínguez: Profesor del Área de Comunicación en la Universidad Complutense de Madrid, Universidad Europea de Madrid y Escuela Superior de Estudios de Relaciones Públicas.

david.caldevilla@ccinf.ucm.es

\section{CURRÍCULUM VITAE}

Diplomado en Magisterio por la Universidad de Zaragoza (España), licenciado en Comunicación Audiovisual por la Universidad Complutense de Madrid (España). Profesor en la Facultad de Ciencias de la Información de la Universidad Complutense. Secretario General del Fórum Internacional de Comunicación y Relaciones Públicas (España) y autor de varios artículos en revistas universitarias. Director de Operaciones de Imagométrica, s.l. y ex directivo de varias firmas españolas del ámbito de la mercadotecnia.

\section{RESUMEN}

La publicación de este artículo coincide con la cercanía de las elecciones europeas. Según algunas encuestas, ocho de cada diez españoles no es capaz de nombrar ningún país de los diez últimos que han sido adscritos a la Comunidad Europea. Esto sumado a otros muchos asuntos, demuestra que el conocimiento de los españoles sobre la marcha de la Unión Europea es nulo. Con este artículo quizás podamos saber algo más al respecto. 


\title{
PALABRAS CLAVE
}

Elecciones europeas - España - Comunidad Europea - Países adscritos

\begin{abstract}
The publication of this article coincided with the approach of the European elections. According to some surveys, eight out of ten Spanish is not able to name any country in the last ten have been assigned to the European Community. This, together with many other issues, shows that knowledge of the Spanish on the progress of the European Union is nil. With this article, maybe we know something more about it.
\end{abstract}

\section{KEY WORDS}

European Elections - Spain - Europe - Countries attached

\section{TEXTO:}

Mi último artículo publicado el mes pasado en esta ágora universitaria que pretende y consigue ser la revista "Vivat Academia" versaba sobre el liderazgo y su importancia en las elecciones generales de marzo de 2004. Ahora toca el turno de saber si los españoles "semos" o no europeos.

En aquel 1986 de nuestros recuerdos, Pedro Ruiz, el humorista televisivo de la nueva cara de la televisión plural posfranquista recordaba a nuestros nuevos compatriotas en un periplo en autobús por las principales capitales europeas, mediante un cartel 
en la trasera de dicho vehículo, que debían sentirse felices pues ya eran españoles por fin. Algo así como "Felicidades europeos, ya sois españoles" pero en bárbaro sajón.

Los europeos, agradecidos supongo, no han dejado de venir a la California del Viejo Continente, a disfrutar de nuestros lares, arena, sol, paella y sangría.

Emocionado compruebo que en el calendario de elecciones para este año, los carpetovetónicos debemos cumplir con el débito democrático de elegir no sólo a nuestros representantes en la Cortes de una España cada vez más federal, sino que hemos de enviar allende nuestras fronteras a los nuevos Tercios, esta vez de políticos encorbatados, a un Flandes ahora ya independiente. Nuestros compatriotas de la estrellada bandera azul harán otro tanto.

Pero he aquí mi sorpresa al ver en la prensa española como una encuesta realizada por "El País" afirma que el $80 \%$ de los españoles no es capaz de nombrar ni un solo país de los diez nuevos adscritos a la Comunidad Europea. ¿Somos europeos?. ¿Ser europeo es un estado mental a imitación de lo que creen los estadounidenses sobre su nacionalidad?.

Los hechos: el pasado miércoles, la Unión Europea procedió a la firma del tratado de adhesión de 10 nuevos miembros, la ampliación más grande jamás registrada en la historia de la UE. Diez nuevos países que proceden (salvo Chipre y Malta, dos excolonias británicas hasta los años 60 del siglo XX) del antiguo bloque del Este y que incorporan sus propias historias e intereses.

Pero, sobre todo, desde un punto de vista español, llegan a la UE sin que parezca que nos hayamos dado por enterados: según datos del barómetro del Real Instituto Elcano, en noviembre de 2002, el 69\% de los españoles no era capaz de nombrar ni a uno solo de los países que iban a ser admitidos como nuevos miembros de la Unión 
Europea. Tres meses después, en febrero de 2003, el desconocimiento era, incluso, superior: el $80 \%$ se sentía incapaz de identificar a uno solo de los 10 nuevos miembros de la UE.

Según la misma encuesta, el $90 \%$ de los españoles reconocía no tener idea de para qué se había convocado una Convención Europea, y solo el 1\% era capaz de decir que su objetivo es la elaboración de una Constitución Europea que permita mejorar el funcionamiento de una Unión ya con 25 miembros y más de 450 millones de habitantes.

El desconocimiento de los españoles sobre la marcha de la Unión Europea es aplastante.

Existe una pequeña explicación, aparte de la obvia geográfica, que sirve para aclarar este fenómeno de aparente invisibilidad: los nuevos miembros de la Unión están, casi todos ellos, mucho más próximos a Alemania, de donde procede la mayor influencia económica y las mayores inversiones, y a Francia, de donde ha llegado una gran influencia cultural, de la mano de becas y ayudas universitarias, que a España.

Caso atípico son las Repúblicas Bálticas y Polonia quienes han pedido y logrado ya su entrada en la OTAN de manera que la vieja Unión Soviética (recordemos que Putin fue Coronel en el Comité para la Seguridad del Estado, más conocido por sus siglas KGB y entre 1998 y 1999 jefe del Servicio Federal de Seguridad o FSB, su sucesor) posee ya frontera común (aparte del caso turco) con sus archienemigos que amenazan ahora, pues no hay peor cuña que la de la propia madera, con ubicar bases de la Alianza allí. No hay mayor fanático que el recién converso. Europa lo permite con el grave riesgo que conlleva soliviantar a nuestros poderosos vecinos fronterizos antes que a los lejanos aliados allende los mares. 
Además, ocho de ellos son países que se alinean estratégicamente con el llamado norte, frente al sur, el Mediterráneo, al que pertenecemos nosotros. Los dos únicos países del ex bloque soviético que se podrían identificar con el sur, Rumania y Bulgaria, han visto precisamente retrasada su adhesión por motivos económicos hasta una segunda etapa.

Todos, salvo Polonia, son países pequeños, nada interesados en las nuevas fórmulas de funcionamiento de la Unión que defiende España. De hecho, la atención primordial del Gobierno español se ha centrado por ahora, casi exclusivamente, en Polonia, un país de un tamaño intermedio similar al nuestro, que tiene una intensa corriente emigratoria hacia España, y con el que compartiremos, en el futuro, un mismo nivel de representación.

Por último, la inversión española en los ocho países que proceden del Este es casi inexistente. Si como cree un $71 \%$ de los españoles (datos obtenidos de la encuesta mencionada), la influencia de un país se mide en buena parte por su capacidad económica, la de España en los nuevos miembros de la UE será casi nula. El Instituto Cervantes es la única entidad que mantiene la presencia española en varios de esos países, aparte de alguna Cámara de Comercio Oficial a pequeño nivel.

En cualquier caso, la última cumbre de la Unión Europea puede haber servido para rebajar la tensión de las últimas semanas y para empezar a recomponer algunos platos rotos. La labor de mediación parece estar encomendada al primer ministro británico, Blair, y al canciller alemán, Schröder, sin que los medios de comunicación europeos den relevancia a los eventuales esfuerzos del Gobierno Español en el mismo sentido.

En el flanco español, sin embargo, se considera que no bastará con la actividad británica para recomponer la unidad interna de la UE ni con las reuniones de los 
cuatro países europeos miembros del Consejo de Seguridad de la ONU. España necesitará hacer un trabajo añadido para mejorar sus propias relaciones bilaterales con franceses, alemanes y belgas.

Estas tensiones son las que han podido provocar un distanciamiento de la Opinión Pública española frente a los asuntos europeos, pero no olvidemos que Bruselas, cada vez más, impone su ley, que poco a poco, constante como una marea, anegará las locales y las nacionales en aras de una nueva globalización política tan necesaria como oportuna.

"Lo natural sería que ese esfuerzo diplomático español fuera inmediatamente correspondido y que las aguas volvieran a su cauce", asegura en El País un funcionario destinado en Bruselas. La falta de espíritu europeo la política española, y la Opinión Pública nacional es reflejo de ello, comienza a poner nerviosa a mucha gente en España, desde los catalanistas históricos hasta la derecha demócrata cristiana.

Sea como fuere Europa, que ha sido como balsa de salvación de los regionalismos más extremos, de los nacionalismos más tibios y de los independentismos más fríos, va a representar el papel de Saturno-Cronos devorando a sus hijos, porque para la nueva Europa todos somos una y la misma cosa. 